\title{
Probability Estimation of Main Function Execution by Fire Warning Detectors
}

\author{
A.N. Ivanov, V.V. Kutuzov, D.P. Keda, O.V. Utkin, A.V. Kondrashin, G.L. Shidlovsky, F.A. Dali \\ Saint-Petersburg University of state fire service of EMERCOM of Russia, Russia
}

\begin{abstract}
This article analyzes the interrelation between probability of main function execution by fire-alarm system main function and predicted evacuation time. As exemplified by probability estimation of main function execution by electro-optical point smoke detector, it has been demonstrated that this target can be aided by fuzzy sets and fuzzy logics. Procedure of development of rule database of fuzzy inference is described.
\end{abstract}

Key words: automatic fire-alarm system, emergency notification system, evacuation time, fire warning detector, probability of primary function execution.

\section{INTRODUCTION}

Rescue services of all countries should solve the problem of fire survival. This problem also concerns administrative bodies of facilities with mass gathering as well as security officers of these facilities.

It is obvious that this problem could be solved only by means of duly and reasonably arranged voice announcement about initiated fire, activation of emergency exit signs depending on fire origin point and possible routes of its propagation with direct participation of responsible persons in the evacuation. In order to develop procedure of efficient crowd control, it is required to provide the most accurate concept of time available for administrators to evacuate all people to safe location depending on scenario of fire development.

This time will be determined by the difference between the time of fire development from initiation to the time when safe evacuation is impossible $\left(t_{\mathrm{cr}}\right)$ and the time $\left(\mathrm{t}_{\mathrm{in}}\right)$ when the fire after its initiation $\left(t_{0}=0\right)$ is detected by automatic fire-alarm system.

Prediction of $\mathrm{t}_{\mathrm{cr}}$ for buildings of certain functional purposes with forecastable routes of fire propagation and known fire loads is not difficult, since various practices are developed for such cases $[1,2]$.

The time $t_{\text {in }}$ can be theoretically determined on the basis of requirements to threshold of activation of various fire-alarm systems stipulated in respective regulations.

In particular, in Russia such regulation is State standard GOST R 53325-2012: Fire techniques. Means of fire automatics. General technical requirements and test methods [3], according to which appropriate authorities certify fire-alarm systems prior to their serial production.

Issued certificate guarantees activation of fire-alarm system when monitored fire properties reach threshold value. However, the time when monitored fire factor reaches threshold value under laboratory conditions and under actual conditions can vary several folds.

During certification, the material combustion is simulated by standard test conditions, when the monitored factor reaches the activation threshold of fire-alarm system always in one and the same time.

Under actual operation conditions of fire-alarm systems, even during the same day in the same room this time will be different and depend on such circumstances as opened or closed windows, air gates, doors, variation of weight or type of combustible material, etc.

In addition, new models of fire-alarm systems are submitted for certification, many manufacturers determine their operation lifetime as ten years. During this period the electronic components are aged and inevitably lose some of their properties. This fact is confirmed by the studies of dynamics of losses of radiation capacity of LEDs depending on operation time [4]. The tests were carried out with about 30 LEDs used as photon emitters in electro-optical smoke detectors. The experimental results are illustrated in Fig. 1. 


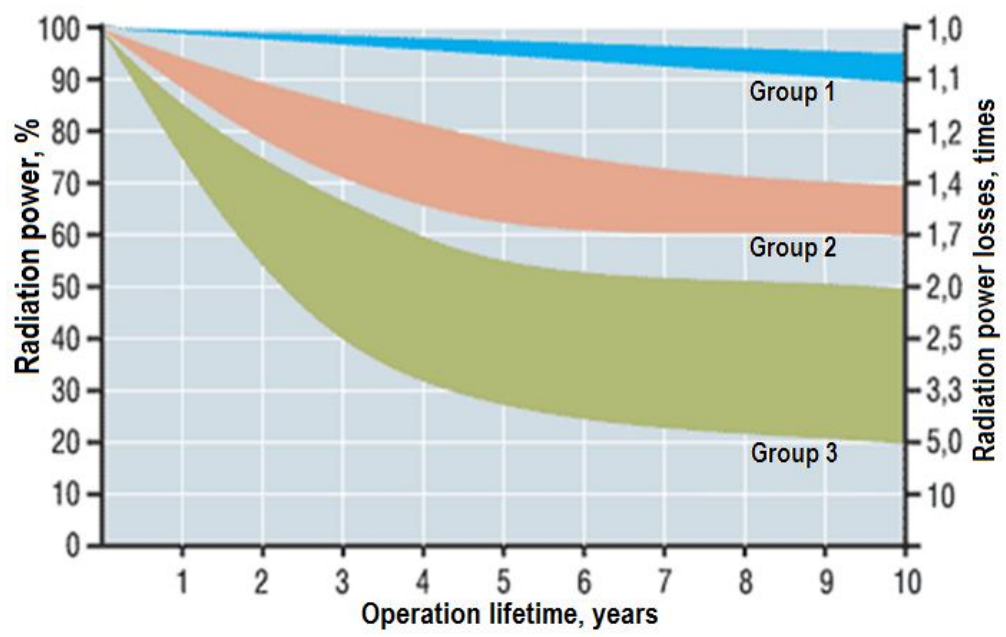

Figure 1: LED radiation power loss as a function of operation lifetime [4].

It can be seen that only few LEDs retained their radiation capacity during overall operation lifetime (Group 1). The LEDs in Group 3, the most numerous, already after two years of operation lost $50 \%$ of their radiation capacity. Knowing the operational principle of electro-optical smoke detectors, it could be reasonably assumed that their activation threshold will be significantly higher than required by regulations. Therefore, the probability of timely detection of fire by such detector will decrease with the increase in its maturity. Hence, the real time of safe evacuation could be significantly lower than the predicted one, which could lead to severe accidents. Thus, the evacuation time should be predicted as follows:

- firstly, with consideration for faultless operation of fire-alarm systems;

- secondly, with consideration for probability of timely fire detection with accounting for ambient conditions.

Therefore, this time cannot be predicted once and for overall lifetime, it should be adjusted from time to time depending on varied conditions effecting the time of fire detection by automatic fire-alarm system. This prediction should be based on probability of timely fire detection by automatic fire-alarm system.

The valid regulations of the Russian Federation for fire safety do not stipulate the term "probability of fire detection" with regard to automatic fire-alarm systems, though, it is considered in definition of "probability of efficient operation of fire-alarm system" in indirect form as "probability of main function execution" [5].

These notions are analyzed in details in [6]; and concerning introduction of the terms "probability of timely fire detection" and "probability of reliable fire detection" there are some interesting proposals in [7].

We believe that the term "probability of main function execution" as applied to automatic fire-alarm systems is more appropriate than "probability of fire detection".

Actually, contrary to intrusion sensors, which are either activated upon intrusion in protected area or not activated, the fire-alarm systems should be activated not later than certain time after occurrence of fire signs. At certain stage of fire development, they will be activated anyhow, wrapped in flames, though, they would not execute their function.

The researchers in [5] recommend to assign the probability of main function execution either to one (upon existing backgrounds to select tools and their location providing predicted detection time), or to zero (if such backgrounds are unavailable).

However, in the case when probability of main function execution can be zero, then it means that the automatic fire-alarm system installed at protected facility is completely out of operation. According to regulations, such situation cannot be allowed. Then, it is impossible to install automatic fire-alarm system without substantiation of its necessity and composition, considering the legally established notion of system lifetime accompanied by arrangement of appropriate documentation duly coordinate and approved at each stage. Then, let us consider the situation when the probability of main function execution can be assigned to one. Such situation is attractive but, unfortunately, inaccessible. As mentioned above, the time of fire detection by fire-alarm system strongly depends on actual ambient conditions as well as the period of operation lifetime of the system, thus, it can differ significantly from that defined in specifications.

It is impossible to estimate probability of main function execution by this or that fire-alarm system (that is, overall system) by methods of probability system and mathematical statistics due to unavailable statistics of operation of automatic fire-alarm systems. While investigating fires, as a rule, only the fact of activation or non-activation of the system is considered.

\section{METHODS}

The methods of fuzzy logics are proposed as a possible tool of probability estimation of main function execution by 
A.N. Ivanov et al., International Journal of Emerging Trends in Engineering Research, 8(3), March 2020, 683- 689

automatic fire-alarm systems.

This can be exemplified by possible sequence of main function execution by smoke, point, electro-optical, threshold fire-alarm systems. This is the most popular type of fire-alarm systems in Russia. The IP 212-141 fire-alarm (Rubezh company) is used as reference.

Let us consider some specifications required for probability estimation of main function execution using fuzzy logics.

According to the specifications, the sensitivity of fire-alarm system corresponds to smoke content of ambient environment attenuating light flux in the range from 0.05 to $0.2 \mathrm{~dB} / \mathrm{m}$; speed of response of fire-alarm system does not exceed $9 \mathrm{~s}$.

Fire-alarm system remains operable under the impact of:

- air flow at the rate up to $10 \mathrm{~m} / \mathrm{s}$;

- background illumination up to 12,000 $\mathrm{lx}$ from artificial or natural light sources.

Operation lifetime is at least 10 years.

The conditions effecting deviation of probability of main function execution by fire-alarm system from one are the maturity and the noise intensity, which can occur in protected rooms (variations of convection air flows related with simultaneously opened doors and windows, operation of ventilation and conditioning systems, etc.).

In order to describe situation in terms of fuzzy logics, let us introduce two linguistic variables: resource maturity degree and noise intensity, which will be used as input variables of fuzzy inference system $[8,9]$.

The output variable of fuzzy inference system is the probability of main function execution by fire-alarm system.

The terms of the linguistic variable "Resource maturity degree" are as follows: low, medium, and high.

According to provisions of fuzzy set theory, each time of operation should be assigned to certain value from zero to one, which determines the degree of membership of this value to this or that term of the linguistic variable "Resource maturity degree". The membership degree is determined by the so called membership function $\mu\left(t_{o p}\right)$, where $t_{\text {op }}$ is the time from the start of operation of fire-alarm system. Association of $t_{o p}$ set with the membership function $\mu\left(t_{o p}\right)$ in terms of fuzzy logics is referred to as fuzzification, that is, conversion of $t_{o p}$ into fuzzy format. The values of membership function $\mu\left(t_{\mathrm{op}}\right)$ can be obtained only from a priori knowledge, intuition (experience), expert interviewing.

The terms of the second input variable "noise intensity" are also low, medium, and high.

The output variable "probability of main function execution by fire-alarm system" is characterized by the following terms: high, medium, low.

The interconnection between input and output can be illustrated by the table of fuzzy rules (Table 1).
Table 1. Probability of main function execution by fire-alarm system

\begin{tabular}{|c|l|l|l|l|}
\hline \multicolumn{2}{|c|}{} & \multicolumn{3}{|l|}{ Resource maturity } \\
\cline { 3 - 5 } \multicolumn{2}{|c|}{} & Low & Medium & High \\
\hline \multirow{2}{*}{$\begin{array}{c}\text { Noise } \\
\text { intensity }\end{array}$} & Low & High & High & Medium \\
\cline { 2 - 5 } & Medium & High & Medium & Low \\
\cline { 2 - 5 } & High & Medium & Medium & Low \\
\hline
\end{tabular}

Each record in this table corresponds to its fuzzy rule:

- It the maturity of fire-alarm system is low and the noise intensity is low, then the probability of main function execution by fire-alarm system is high;

- It the maturity of fire-alarm system is high and the noise intensity is medium, then the probability of main function execution by fire-alarm system is low; etc.

In order to plot membership function, experts' opinion is required to assign certain number from zero to one to each value of linguistic variable, it will determine the degree of membership of this value to this or that term.

\section{RESULTS}

The following expert appraisals were obtained (see Table 2-4).

Table 2. Expert appraisal of resource maturity

\begin{tabular}{|c|c|l|}
\hline $\begin{array}{l}\text { Maturity of } \\
\text { fire-alarm } \\
\text { system }\end{array}$ & $\begin{array}{l}\text { Appraisal criterion of } \\
\text { resource maturity }\end{array}$ & Values \\
\hline Low, $\mathrm{i}=1$ & $\begin{array}{c}\text { Fire-alarm system operated } \\
\text { during less than 25\% of } \\
\text { design service life }\end{array}$ & $0-0.20$ \\
\hline Medium, i =2 & $\begin{array}{c}\text { Fire-alarm system operated } \\
\text { during from 25\% to 50\% of } \\
\text { design service life }\end{array}$ & $0.2-0.50$ \\
\hline High, $\mathrm{i}=3$ & $\begin{array}{c}\text { Fire-alarm system operated } \\
\text { during more than 50\% of } \\
\text { design service life }\end{array}$ & $0.5-1.0$ \\
\hline \multicolumn{3}{|c|}{} \\
\hline
\end{tabular}

Table 3. Expert appraisal of noise intensity

\begin{tabular}{|c|c|l|}
\hline $\begin{array}{l}\text { Noise } \\
\text { intensity }\end{array}$ & $\begin{array}{l}\text { Appraisal criterion of noise } \\
\text { intensity }\end{array}$ & Values \\
\hline Low, $\mathrm{j}=1$ & $\begin{array}{c}\text { Single noise source, its } \\
\text { intensity does not exceed } \\
\text { background level more than by } \\
20 \%\end{array}$ & $0-0.20$ \\
\hline $\begin{array}{c}\text { Medium, } \mathrm{j}= \\
2\end{array}$ & $\begin{array}{c}\text { At least two noise sources, } \\
\text { their intensities do not exceed } \\
\text { 20\% of background level, or } \\
\text { one type noise with the } \\
\text { intensity in excess of from 20\% } \\
\text { to 40\% }\end{array}$ & $0.20-0.40$ \\
\hline High, $\mathrm{j}=3$ & $\begin{array}{c}\text { Noise intensity exceeds } \\
\text { background level by } 40 \% .\end{array}$ & $0.40-1.0$ \\
\hline
\end{tabular}


A.N. Ivanov et al., International Journal of Emerging Trends in Engineering Research, 8(3), March 2020, 683- 689

Table 4. Expert appraisal of probability of main function execution by fire-alarm system

\begin{tabular}{|c|l|l|}
\hline $\begin{array}{l}\text { Probability of } \\
\text { main function } \\
\text { execution by } \\
\text { fire-alarm } \\
\text { system }\end{array}$ & $\begin{array}{l}\text { Appraisal criterion of } \\
\text { probability }\end{array}$ & Values \\
\hline High, $\mathrm{k}=1$ & $\begin{array}{l}\text { The installed in protected } \\
\text { room fire-alarm systems } \\
\text { are characterized by } \\
\text { medium resource maturity } \\
\text { and low or medium } \\
\text { intensity of noises }\end{array}$ & $0.90-0.80$ \\
\hline Medium, $\mathrm{k}=2$ & $\begin{array}{c}\text { The installed in protected } \\
\text { room fire-alarm systems } \\
\text { are characterized by low } \\
\text { resource maturity and high } \\
\text { intensity of noises, or } \\
\text { medium resource maturity } \\
\text { and medium or high } \\
\text { intensity of noises, or high } \\
\text { resource maturity and low } \\
\text { intensity of noises }\end{array}$ & \\
& $\begin{array}{c}\text { The installed in protected } \\
\text { room fire-alarm systems } \\
\text { are characterized by high } \\
\text { resource maturity and } \\
\text { medium or high intensity } \\
\text { of noises }\end{array}$ & \\
\hline Low, $\mathrm{k}=3$ & $0.70-0.60$ \\
\hline \multirow{2}{*}{. 0.70} \\
\hline
\end{tabular}

The following notations were introduced for further data processing:

1. Resource maturity: X;

2. Noise intensity: Y;

3. Probability: Z;

4. Number of possible variants: $\mathrm{N}$;

5. Indices: $\mathrm{i}, \mathrm{j}, \mathrm{k}$.

Then, the rule database presented in the form of fuzzy statements corresponding to membership functions will be as follows:

1: IF Resource $=\mathrm{Xi}$ AND Noise intensity $=\mathrm{Yj}$, THEN Probability $=\mathrm{Zk}$,

2: IF Resource $=\mathrm{Xi}$ AND Noise intensity $=\mathrm{Yj}$, THEN Probability $=$ Zk,

$\mathrm{N}$ : IF Resource $=\mathrm{Xi}$ AND Noise intensity $=\mathrm{Yj}$, THEN Probability $=\mathrm{Zk}$

where $\mathrm{i}=1,2,3 ; \mathrm{j}=1,2,3 ; \mathrm{k}=1,2,3$.

Then, using the obtained rule database, it is possible to perform computer simulation of probability estimation of main function execution by fire-alarm system. The results obtained in MATLAB are illustrated in Figs. 2-7 [9].

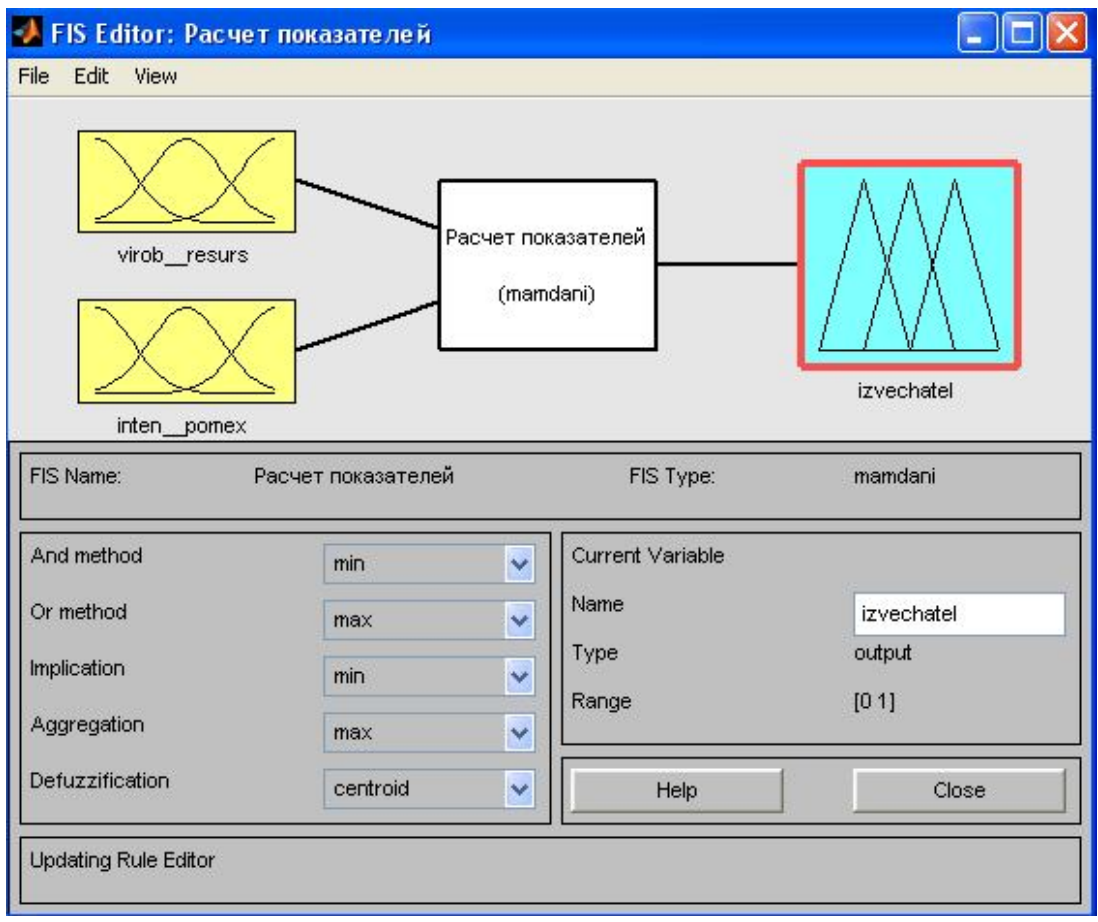

Figure 2: Graphical interface of fuzzy inference system editor 
A.N. Ivanov et al., International Journal of Emerging Trends in Engineering Research, 8(3), March 2020, 683- 689

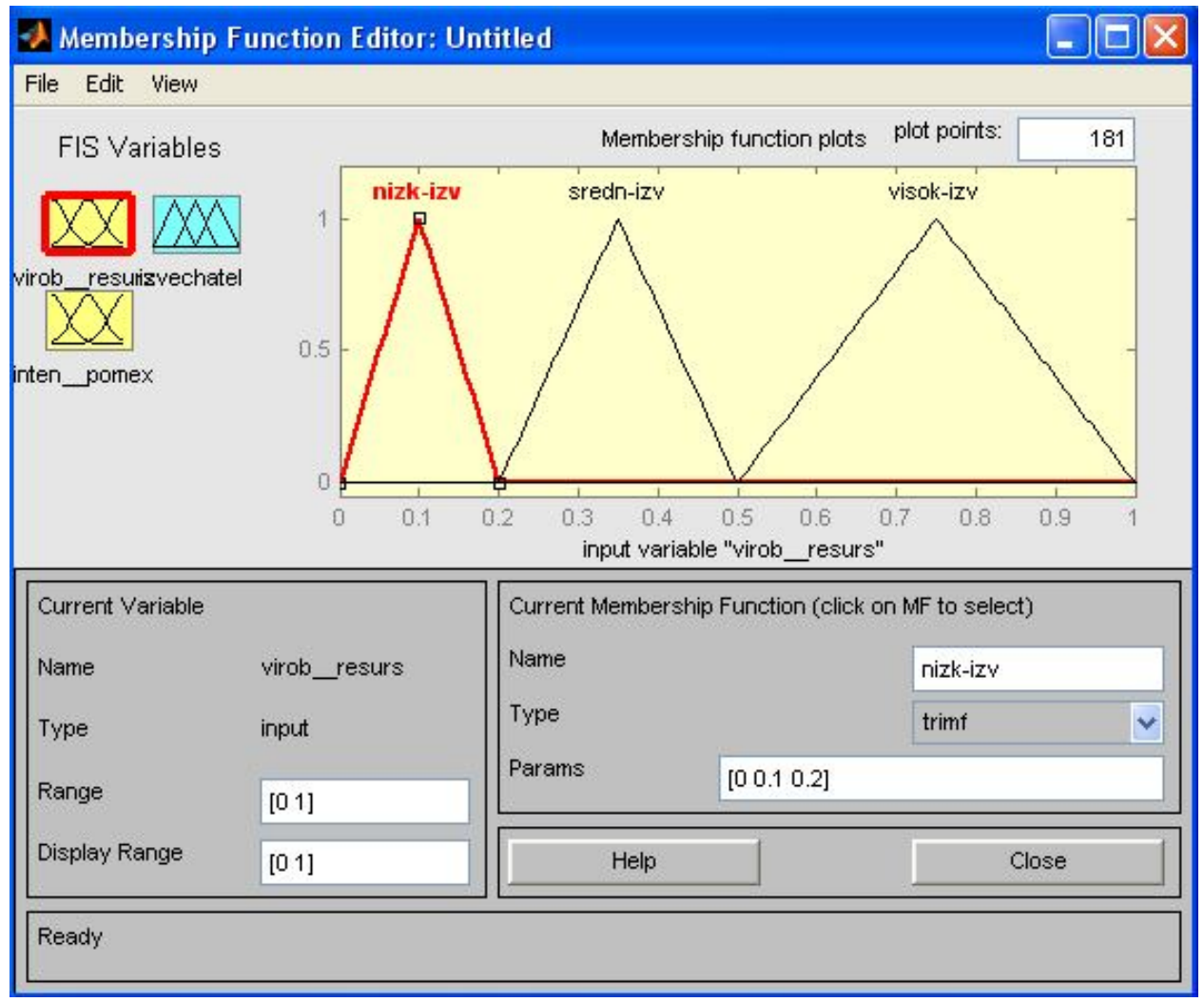

Figure 3: Membership function for input variable: Resource maturity

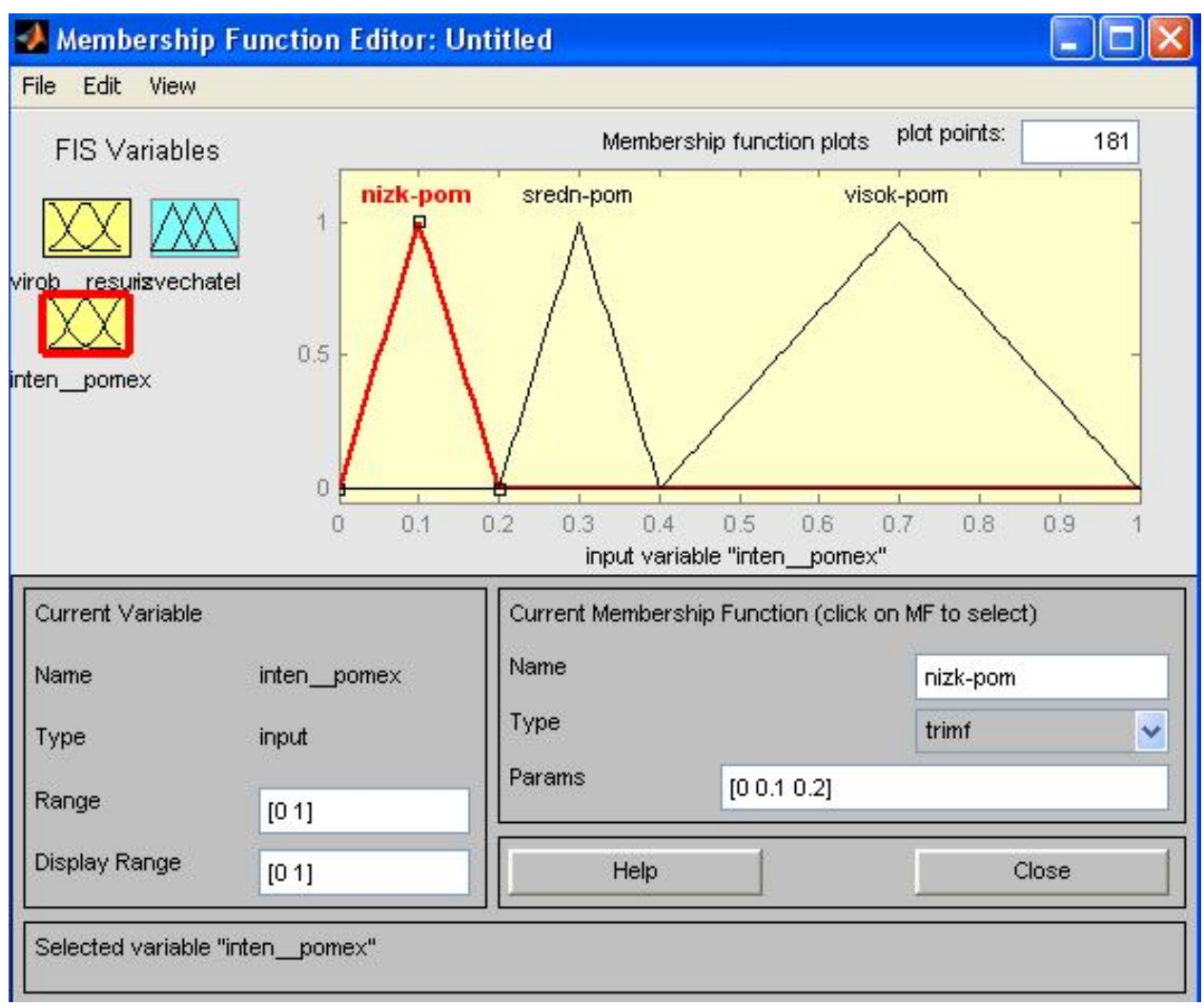

Figure 4: Membership function for input variable: Noise intensity 
A.N. Ivanov et al., International Journal of Emerging Trends in Engineering Research, 8(3), March 2020, 683- 689

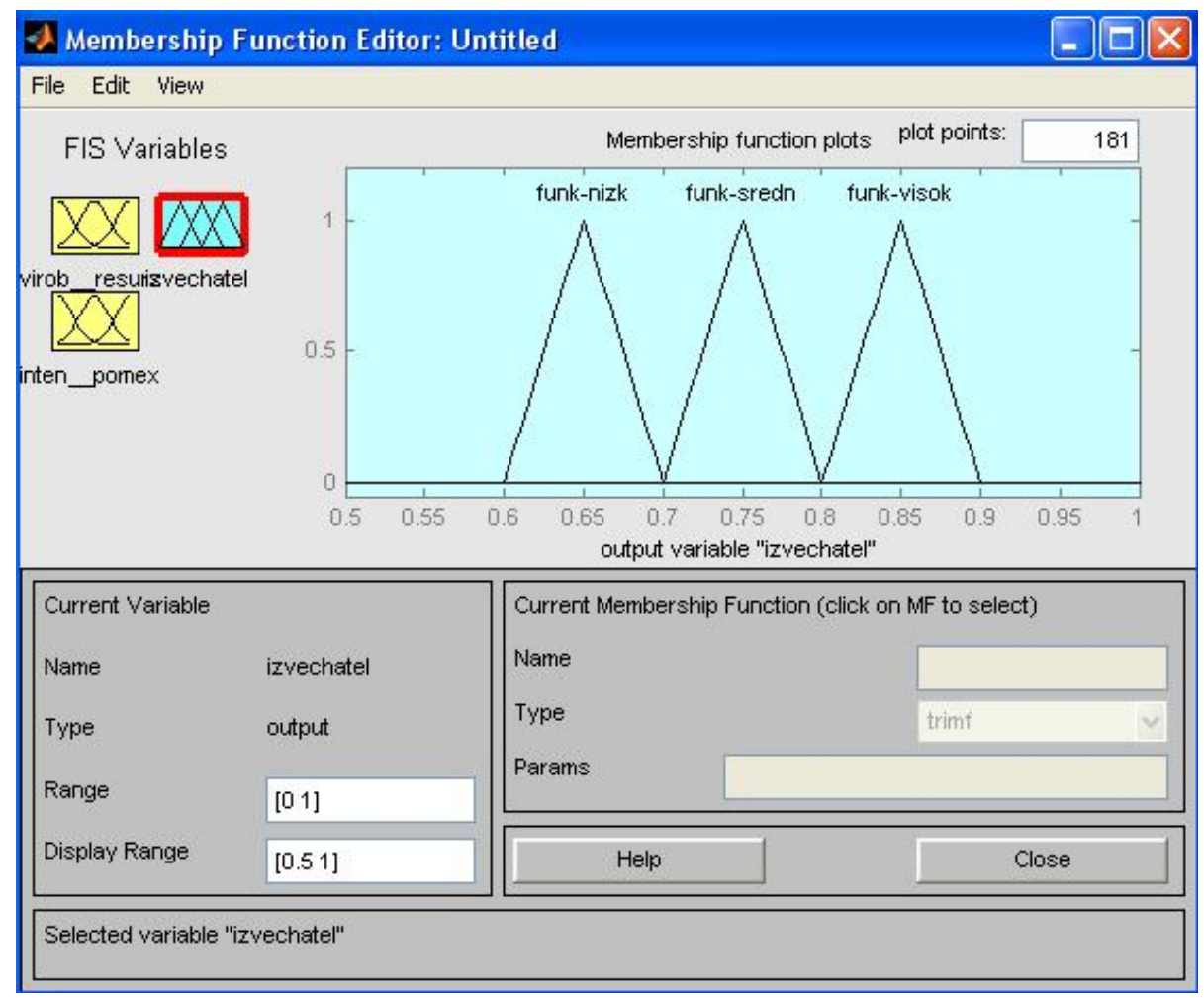

Figure 5: Membership function for input variable: Probability of main function execution by fire-alarm system

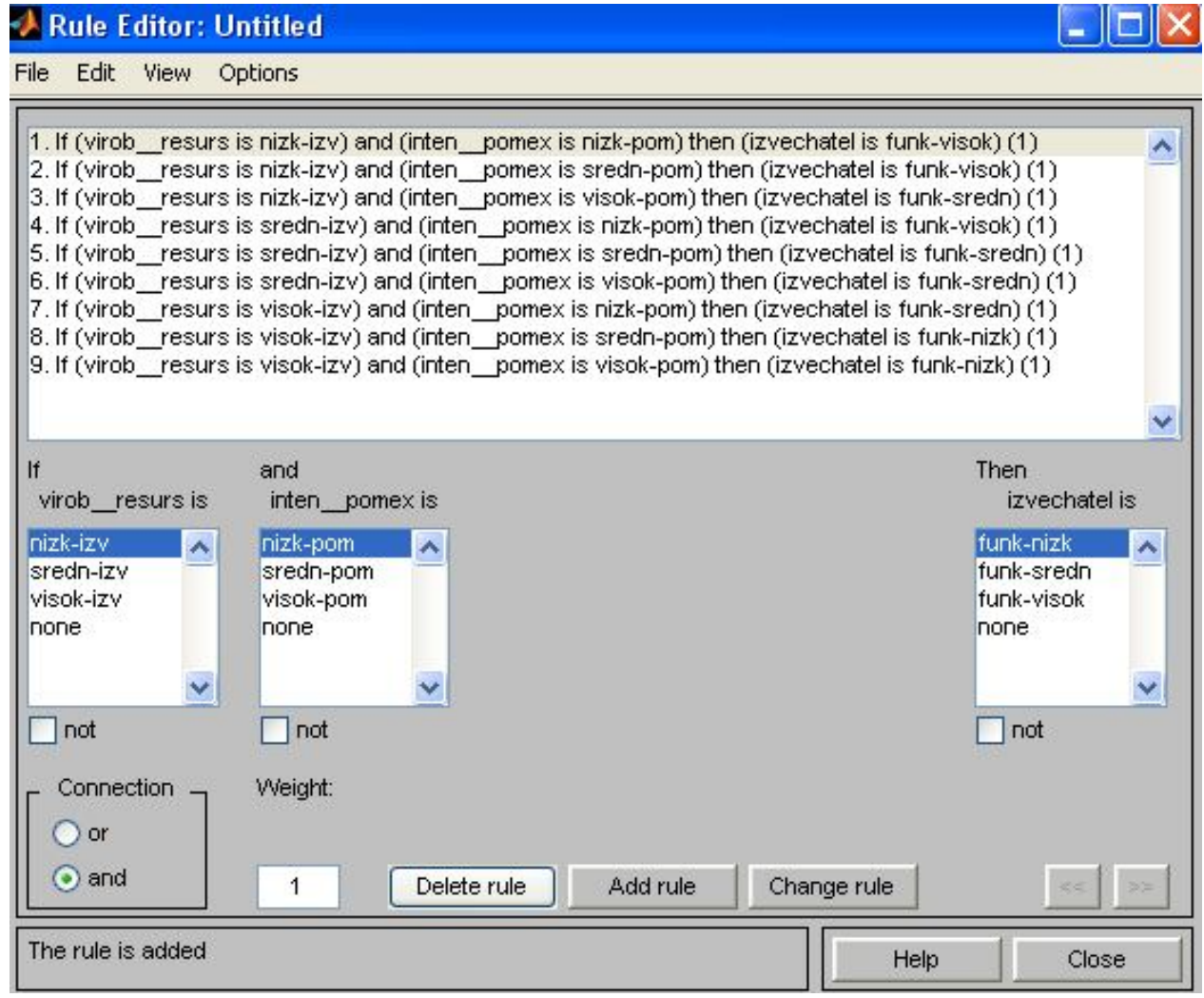

Figure 6: Rule database of fuzzy inference system

The rule database viewer makes it possible to visualize the results of fuzzy inference and output variables upon preset of initial input variables (Fig. 7). 


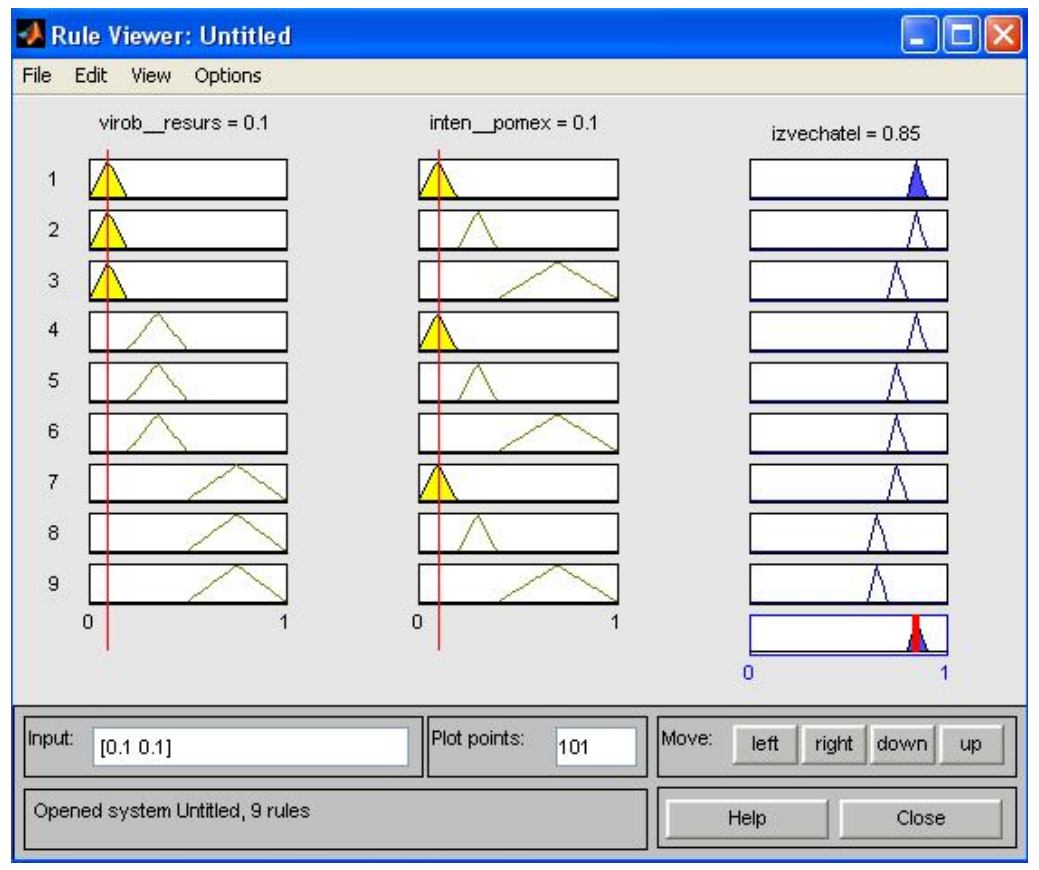

Figure 7: Fuzzy inference for inputs ([0,1;0,1] in Input field).

\section{CONCLUSION}

The described example demonstrates application of fuzzy logics for probability estimation of main function execution by fire-alarm systems under actual conditions. More than two input variables can exist in reality depending on the type of applied fire-alarm systems and conditions of their operation. Each variable should be based on the operational principle of the considered fire-alarm systems and place of their location. It would obviously require both time and involvement of experts. Herewith, the obtained probability estimation of main function execution by fire-alarm systems would allow to estimate more accurately the time which can be relied on during evacuation of people at certain facility and at predetermined scenario of fire progress.

\section{REFERENCES}

1. State standard GOST 12.1.004-91. Occupational safety standards system. Fire safety. General requirements (with Revision N1).

2. Order of RF Emercom N 382. On adoption of procedure of predictions of fire risks in buildings, facilities, and structures of various classes of fire hazard (with modifications and addenda). June 30, 2009.

3. State standard GOST R 53325. Fire techniques. Means of fire automatics. General technical requirements and test methods, 2012.

4. 4. I. Pivinskaya. Proverka vremenem. Ee ne vsegda vyderzhivaet chuvstvitel'nost' pozharnykh izveshchatelei [Tested by time. Sensitivity of fire-alarm systems sometimes fails]. BDI, 4(55), 2004.
5. Commentaries to certain articles of Federal law №123-FZ. Regulations to fire safety requirements. July 22, 2008. Available at: http://www/vniipo/resources/Comment_123_FZ_2011/z ip

6. Ya. Mironenko. Veroyatnost' effektivnoi raboty tekhnicheskikh sredstv obespecheniya pozharnoi bezopasnosti [Probability of efficient operation of fire safety appliances]. Algoritm bezopasnosti, 6, 2014.

7. A. Zaitsev. Dostovernost' i svoevremennost' obnaruzheniya pozhara, i kak ikh uchest' v normakh na SPS [Reliability and timeliness of fire detection, how they can be accounted in regulations for fire-alarm systems]. Algoritm bezopasnosti, 2, 2016.

8. A.Yu. Labinskii, O.V. Utkin. Sistema nechetkogo vyvoda s nechetkimi funktsiyami prinadlezhnosti [Fuzzy inference system with fuzzy membership functions]. Vestnik Sankt-Peterburgskogo universiteta GPS MChS Rossii, 1, pp. 68-74, 2016.

9. A.V. Leonenkov. Nechetkoe modelirovanie $\mathrm{v}$ srede MATLAB i fuzzyTECH [Fuzzy simulation in MATLAB and fuzzyTECH]. St. Petersburg: BKhV-Petersburg, 2005.

10. N.V. Kamenetskaya, O.M. Medvedeva, A.A. Gorbunov, S.B. Khitov, I.V. Smirnova. Application of the sequential analysis method in the justification of optimal managerial decisions in the context of uncertainty. Espacios, 40(35), pp. 15, 2019. 